\title{
Alcohol Effects on the P2 component of Auditory Evoked Potentials
}

\author{
OSCAR H. HERNÁNDEZ ${ }^{1,2}$, ROLANDO GARCÍA-MARTÍNEZ ${ }^{1}$ and VÍCTOR MONTEÓN ${ }^{1}$ \\ ${ }^{1}$ Centro de Investigaciones Biomédicas y Cuerpo Académico Biomedicina, \\ Universidad Autónoma de Campeche, Avenida Agustín Melgar sin número entre Juan de la Barrera y calle 20. \\ Colonia Buenavista, San Francisco de Campeche, Campeche, Código Postal 24039, México \\ ${ }^{2}$ Hospital General de Especialidades "Dr. Javier Buenfil Osorio", Secretaría de Salud. \\ Av. Lázaro Cárdenas No. 208, San Francisco de Campeche, Campeche, Código Postal 24039, México
}

Manuscript received on July 22, 2013; accepted for publication on November 11, 2013

\begin{abstract}
This is a second part of a research aimed to study the effects of alcohol on the electrophysiological processes in student volunteers. The first part showed that alcohol slowed the Omitted Stimulus Potential (OSP). This work studied the ethanol effects on the parameters (i.e. rate of rise, amplitude and peak latency) of the P2 component of the evoked potentials (EPs) yielded by trains of auditory stimuli. It is hypothesized here that if $\mathrm{P} 2$ and OSP waves share some common neural processes then alcohol should also affect these specific parameters. A dose of $0.8 \mathrm{~g} / \mathrm{kg}$ of alcohol or a placebo $(0 \mathrm{~g} / \mathrm{kg})$ was administered to two groups of 15 young men who were tested before and again after treatment. The pre-post treatment change in each of the measurements was used to assess the treatment effects. The results showed that compared to placebo, alcohol slowed the P2 rise rate and reduced its amplitude, with no effects on peak latency. The rise rate is more sensitive to alcohol but more resistant to the adaptation process. Alcohol resembles the response inhibition model acting against the adaptation. The rise rate of the P2 and the OSP waves are affected by alcohol in a similar fashion, suggesting similar neural generative mechanisms.
\end{abstract}

Key words: Alcohol, auditory, evoked potentials, parameters.

\section{INTRODUCTION}

In a recent study, Hernández and Vogel-Sprott (2010a) found that parameters of the omitted stimulus potential (OSP) are sensitive to a moderate acute dose of alcohol. The OSP is a phenomenon that occurs at the end of a train of sensory stimuli and is considered a subclass of ERPs that appears to the unpredictable cessation of a repeated stimulus and involves some endogenous, moderately high-level cognitive process (Bullock et al. 1994, Donchin and

Correspondence to: Oscar Hernando Hernández

E-mails: ohhernan@uacam.mx /

ohhernan@yahoo.com.mx
Isreal 1980, Hillyard and Picton 1979, Pritchard 1981, Sutton et al. 1965, 1967). A train-stimulus paradigm also offers the opportunity to study the complete set of parameters (i.e. peak latency, amplitude and rate of rise) of the P2 component of the auditory evoked potentials (EPs), their shortterm adaptation process (Prosser et al. 1981, Polich et al. 1988, Johnson and Yonovits 2007) and their sensitivity to acute dose of alcohol.

The $\mathrm{P} 2$ is a robust averaged positive wave that occurs from the beginning of the train after each stimulus with peak latency around $200 \mathrm{~ms}$. Shortterm adaptation or habituation is common in late 
evoked potentials and is defined as a decline in the amplitude of the responses to repeated stimuli delivered at constant intensity and repetition rate (Picton and Hillyard 1974, Prosser et al. 1981, Polich et al. 1988, Johnson and Yonovits 2007). Most previous studies have reported on reductions in amplitude associated with habituation. However, there is much less consensus about the changes in the peak latency, which can increase or decrease during the process of habituation (Polich et al. 1988, Johnson and Yonovits 2007).

The amplitude and the peak latency are the most common measures used in cortical potentials. In general terms, fluctuation in the amplitude of the brain waves represent variations in the engagement of information-processing operations, whereas variations in the latency of a particular peak indicate differences in the processing speed (Rugg and Coles 1995). Although it is not common to measure the rate of rise, Hernández and VogelSprott (2009), showed that this parameter, in $\mu \mathrm{V} /$ $\mathrm{ms}$, is able to provide a dynamic measure related to the velocity of the engagement processes of neurons, an information not obtained by amplitude or latency measures. A dose of $0.8 \mathrm{~g} / \mathrm{kg}$ alcohol was able to slow the OSP rate of rise and latency, but not significantly reduce its amplitude (Hernández and Vogel-Sprott 2010a). Many reports have demonstrated alcohol-related reductions in the amplitude of either mid- or late-latency components of the cortical potentials (Wolpaw and Penry 1978, Jääskeläinen et al. 1996, Porjesz and Begleiter 1996, Martin and Garfield 2006), although some studies report amplitude increases (Bartholow et al. 2003b, Easdon et al. 2005). The same conflicting results (opposite effects by alcohol) have been found in latency measurements (Rohrbaugh et al. 1987, Sommer et al. 1993, Bartholow et al. 2003a, b). Bimodal effects have also been observed in the N1-P2 amplitude, being small on the first part of the test and large on the second part as compared to placebo values (Krogh et al. 1978, Sommer et al. 1993, Marinkovic et al. 2004). At present, the alcohol effects on the complete set of $\mathrm{P} 2$ parameters and their habituation process have not been studied.

This paper reports the second part of an experiment aimed to study the acute alcohol effects on the averaged brain potentials, evoked during trains of auditory stimuli; the first part examined alcohol effects on reaction time and the OSP (Hernández and Vogel-Sprott 2010a). The present paper deals with alcohol effects on the P2 waves that occur from the beginning of the train. The main goal is to extend our previous alcohol-related electrophysiological findings showing that parameters of $\mathrm{P} 2$ are sensitive to moderate doses of alcohol in healthy volunteers. If $\mathrm{P} 2$ and OSP share some neural mechanisms in their intrinsic parameters, then a factor that alters OSP should similarly change the corresponding P2 parameters. A moderate dose of alcohol is an example of such a factor that has potentially important safety implications for brain functioning because it can impair some components of the cortical waves and the behavior (Hernández and Vogel-Sprott 2010a). No research has yet examined the effect of alcohol on the rate of rise of the P2 component. Averaged recordings from the first, second and the third stimuli on a train offer a great opportunity to ascertain the shortterm adaptation process of the $\mathrm{P} 2$ parameters and their sensitivity to acute alcohol.

\section{MATERIALS AND METHODS}

The task stimuli and electrophysiological recordings procedure are fully explained elsewhere (Hernández and Vogel-Sprott 2010a, b), and are briefly described here.

\section{PARTICIPANTS}

Thirty Hispanic male college students with a mean age of 20.7 years $(S D=2)$ were randomly assigned to one of two groups ( $n=15$ /group): 0.8 grams of alcohol per kilogram of body weight or placebo. All were 
healthy and none had any history of nervous system diseases or motor disability. They were psychology students recruited by direct invitation around the university. The legal drinking age in Mexico is 18 years. All students selected agreed to participate in the experiment and were informed about the procedures before providing informed consent. They had an overnight fast and were required to abstain from alcohol for at least 72 hours. The experiment was reviewed and approved by the Ethics Committee of the University of Campeche, Mexico.

\section{APPARATUS AND MATERIALS}

Train Stimuli and Recordings. The task consists of trials that present repeated auditory stimuli at 2 sec intervals (i.e., $.5 \mathrm{~Hz}$ ) and cease unpredictably. A given trial presents a random number of three to eight stimuli before the stimulus is withheld and the trial ends. Auditory clicks were generated through an electrical stimulator (Grass S48, AstroMed, Inc., West Warwick, RI) and delivered to both ears through headphones. The auditory threshold was determined at the beginning of the experiment by increasing the click voltage until the subject reported its perception, and setting the voltage at 20 times the threshold for the experiment. At this intensity, each subject reported a clear and comfortable listening to the auditory stimuli. The EEG data were obtained with surface disk electrodes (Grass F-E5H) and the active electrode was placed at the $\mathrm{Cz}$ location (international 10/20 system; $<5 \mathrm{k} \Omega$ impedance). The reference was on the left ear and the grounded electrodes were on both ears. Bilateral EOG recordings of eye blink artifacts were identified by its amplitude and removed off-line. The bioelectrical signals were amplified via AC amplifiers (Grass P511) with 60 $\mathrm{Hz}$ notch filters and the output was sent through steep analog bandpass filters set at $0.3-100 \mathrm{~Hz}$ for the EEG and 1-1000 Hz for the EOG. The signals were digitized at $1000 \mathrm{~Hz}$ and collected on-line on an IBM-compatible computer through the
MP100 System. A test on the task consisted of 32 consecutive trials. The EEG records were averaged off-line by AcqKnowledge software (v. 3.7.3., BIOPAC Systems, Inc., 2003, Santa Barbara, CA, USA). Time epochs of at least 6 seconds were used since the beginning of the train in order to include the whole first, second and third P2 waves. Steep digital low pass filters removed alpha or higher frequency components. This is convenient because it is well known that alpha is exacerbated by the requirement that the participants close their eyes, but all activity of interest (P2 waves) is less than $5 \mathrm{~Hz}$. The occurrence of a P2 wave was identified on each averaged record by its robust positive deflection after each auditory stimulus since the beginning of a train. The N1 corresponded to the most prominent negative peak between 90-130 $\mathrm{ms}$, and $\mathrm{P} 2$ was the most prominent positive peak between 150-250 ms (Teo and Ferguson 1986) (see Figure 1). Only the first three EPs on a train were analyzed because the most significant changes in amplitude in the adaptation process are between the first and the second responses; after this, amplitude remains stable (Prosser et al. 1981). These voltage changes are several times higher than the preceding ongoing EEG activity and are easily identified visually. All measures from averaged records were calculated by automatic algorithms included in the AcqKnowledge software. Peak to peak amplitude (in $\mu \mathrm{V}$ ) was calculated for N1-P2 (Prosser et al. 1981, Teo and Ferguson 1986). P2 rise rate is the regression coefficient that describes the microvolts per unit change in milliseconds. This measure is represented as microvolts per milliseconds $(\mu \mathrm{V} /$ $\mathrm{ms}$ ), and calculates the slope of the straight line that intersects the selected area (i.e., from N1 to P2). The peak latency of $\mathrm{P} 2$ is measured by the total time (in milliseconds) from the corresponding applied stimulus until the peak of the EP is attained. Figure 1 illustrates the temporal course of the first, second and third averaged EPs waves from a representative subject during baseline and experimental trials. 


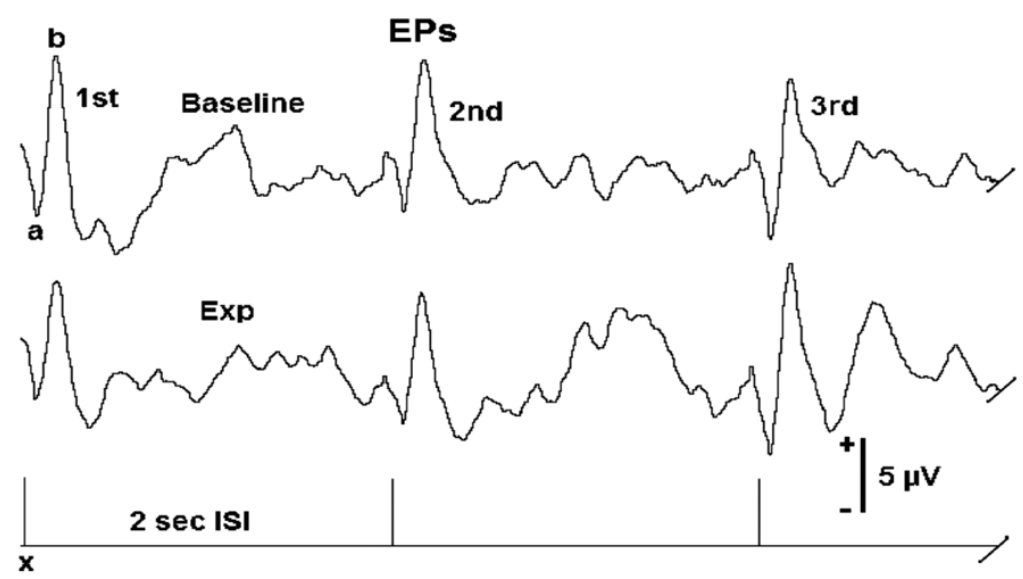

Figure 1 - Example of the first three P2 waves of the evoked potentials (EPs) recorded before (Baseline) and after (Exp) a subject received the drink in the alcohol group. The horizontal axis represents the 2-sec ISI train of auditory stimuli with the auditory stimuli represented by the vertical lines. The upper traces are the averaged 32-EEG records showing that each stimulus produces a corresponding EP. The onset (N1) and peak (P2) of the EPs are identified by a and b, respectively. The latency to peak was measured in the segment $\mathrm{x}-\mathrm{b}$. The slope of a straight line joining the segment a-b identifies the rate of rise. Peak-to-peak amplitude is the magnitude of the wave from a-b (N1-P2).

Beverage Rating Scale. This scale has been used in previous alcohol research to assess the credibility of a placebo (e.g., Fillmore and VogelSprott 1997, Hernández et al. 2007, Hernández and Vogel-Sprott 2010a). Participants were asked to rate the alcohol content of their beverages in terms of standard sized drinks of distilled spirits or bottles of $5 \%$ alcohol beer. The scales ranged from zero to 10 , and ratings in liquor were converted to the equivalent bottles of alcohol beer.

Drinking History Questionnaire. A Spanish translation of the Drinking History Questionnaire (Vogel-Sprott 1992) applied to each participant provided four measures of current typical drinking habits: weekly frequency of drinking typical dose (milliliters of alcohol per kilogram of body weight), duration (hours), and rate of drinking (dose/duration). Additional questionnaire items served to screen for problems related to drinking, but no participant reported on any alcohol-related problems.

\section{PRocEDURE}

Participants were asked to arrive at 8:00 a.m. on the day of the experiment and the task was explained before they signed the consent forms. After they confirmed that they had adhered to the fasting and alcohol restrictions, their zero BACs were verified by breath samples measured by an Alco-Sensor IV (Intoximeters Inc., Mod. 13-0360-10, St. Louis, MO, USA). Participants completed the Drinking History Questionnaire. After the electrodes were attached, participants sat in a chair with their eyes closed during a trial. They were told that they would perform a set of passive trials requiring the participant to simply listen for the occurrence of the stimuli. To ensure that attention was maintained during the test, participants were asked to count the number of stimuli presented during a trial, and to report the number of stimuli after each trial. Prior to beginning the experiment, participants were familiarized with the auditory clicks and the test by performing ten trials.

A drug-free (baseline) test of 32 trials was administered before the groups received a drink (which was "zero time"), served in two glasses and consumed within 10 minutes. One group received $0.8 \mathrm{~g} / \mathrm{kg}$ alcohol in the form of vodka mixed with orange juice in a ratio of one part alcohol to three parts juice. The other group received a placebo equal to the fluid equivalent of the alcohol drinks 
and containing only orange juice. A small amount (5 ml) of alcohol was floated on the surface of each placebo drink, and the glasses were wiped with vodka to enhance the alcohol scent of the placebo beverage. Drinkers receiving this type of placebo commonly report that it contains alcohol (e.g., Fillmore and Vogel-Sprott 1994, 1995, Hernández et al. 2006, 2007, Hernández and Vogel-Sprott 2010a). After the drink was consumed, each participant rinsed his mouth with water in the next ten minutes, to remove any residual alcohol. Twenty minutes after the drinking session began; the treatment (experimental) test of 32 trials was performed. Participants' BAC measures were obtained before and after the set of trials were completed. Subsequent BAC measures were also taken every 13-18 min for 2-3 hours. Participants then completed the Beverage Rating Scale, were debriefed, and received a standard snack. Those who received alcohol remained at leisure in the laboratory until their BACs had declined to a safe level $(<30 \mathrm{mg} / 100 \mathrm{ml})$.

Data Analyses. The dependent variables measured were, rate of rise, amplitude and peak latency of the $\mathrm{P} 2$ wave. The dynamics of the three EPs parameters according to its ordinal position were analyzed separately in drug-free (baseline) conditions by a 3 (ordinal position) repeated measures analysis of variance (ANOVA); a Bonferroni post hoc test was used to adjust the alpha level. Partial Eta-squared $\left(\eta^{2}\right)$ provided the size effects in ANOVA. For each P2 ordinal position, separate linear regressions were used to test the relationship between parameters. The pretreatment drug-free scores were used as a baseline to evaluate treatment effects. For each measure, a participant's pretreatment test score was subtracted from his treatment test score. The treatment-induced change in each of the dependent variables was tested by independent t-tests comparing the alcohol and placebo groups (Hernández et al. 2006, 2007, Hernández and Vogel-Sprott 2010a). The Cohen's $\mathrm{d}$ was used to measure the sample size effects for t-test comparisons. A $P$ value lower than .05 , was considered significant. A total of $1 \%$ of the trials was lost to EOG or other artifacts.

\section{RESULTS}

DRINKING HISTORY

T-tests of each score on the Drinking History Questionnaire obtained no group differences ( $P S$ $>.11$, Cohen's $d s<.46)$; then, the entire sample $(\mathrm{N}=30)$ reported a mean frequency of $.58(S D$ $=0.80$ ) drinking occasions per week with an average duration of 3.32 hours $(S D=2.82)$ and a mean reported dose per occasion of $1.16 \mathrm{ml} / \mathrm{kg}$ $(S D=0.78)$ of alcohol. Assuming an average body weight of $70 \mathrm{~kg}$, this represents the consumption of $4.8341-\mathrm{ml}$ bottles of $5 \%$ alcohol beer during a 3.32- hour drinking occasion and a drinking rate of 1.4 bottles per hour. The drinking habit scores of the sample are comparable to those reported by Canadian students (Vogel-Sprott 1992).

\section{Drug-Free Baseline Performance}

The baseline measures were analyzed to verify that the performance of the two groups did not differ prior to their treatments. T-tests comparing the groups' baseline scores of the rate of rise, amplitude and the peak latency in the P2 component were not significant ( $P s>.25$; Cohen's $d s<.16$ ); then, the entire sample $(\mathrm{N}=30)$ was used to study the dynamics of the EPs parameters. The mean $(S D)$ of each of these measures is shown in Table I.

The 3 (ordinal position) repeated measures analysis of variance (ANOVA) of the EPs rate of rise was significant, $(\mathrm{F} 2,58=5.99, P<.004$, $\eta^{2}=0.171$ ) (fig. 2A). Paired comparisons with a Bonferroni test indicated that the first response was swifter than the second $(P<.03)$ and the third $(P$ $<.05)$, however no difference was found between the last two responses $(P>.05)$. A main effect of the baseline measures was also found in the P2 amplitude $\left(\mathrm{F} 2,58=4.61, P<.014, \eta^{2}=0.137\right)$; 
TABLE I

Mean (SD) measures of the $P 2$ component of the auditory evoked potentials on the drug-free baseline test $(N=30)$, and the mean (SD) change in this measures in placebo or alcohol treatment groups $(n=15)$, according to their ordinal position.

\begin{tabular}{|c|c|c|c|c|}
\hline Measures & $\begin{array}{l}\text { Baseline } \\
\text { M (SD) }\end{array}$ & $\begin{array}{l}\text { Placebo } \\
\text { M (SD) }\end{array}$ & $\begin{array}{l}\text { Alcohol } \\
\text { M (SD) }\end{array}$ & $\begin{array}{c}\text { Cohen's } \\
\text { d }\end{array}$ \\
\hline \multicolumn{5}{|c|}{ Rate of rise $(\mu \mathrm{V} / \mathrm{ms})$} \\
\hline First & $.0659(.030)$ & $-.0051(.015)$ & $-.0325(.032)^{* *}$ & 1.099 \\
\hline Second & $.0531(.019)$ & $.0054(.013)$ & $-.0173(.020)^{* * *}$ & 1.311 \\
\hline Third & $.0550(.021)$ & $.0055(.019)$ & $-.0076(.021)^{*}$ & 0.647 \\
\hline \multicolumn{5}{|c|}{ Amplitude $(\mu \mathrm{V} / \mathrm{ms})$} \\
\hline First & $7.63(3.43)$ & $-.339(1.96)$ & $-3.35(3.08)^{* *}$ & 1.165 \\
\hline Second & $6.16(2.42)$ & $.212(1.55)$ & $-2.48(3.16)^{* *}$ & 1.083 \\
\hline Third & $6.70(2.87)$ & $.249(2.35)$ & $-1.24(2.73)$ & 0.583 \\
\hline \multicolumn{5}{|c|}{ Latency (ms) } \\
\hline First & $223.4(29.9)$ & $-12.4(29.1)$ & $-13.4(50.3)$ & 0.024 \\
\hline Second & $198.3(31.9)$ & $-19.9(24.7)$ & $-10.0(27.8)$ & -0.378 \\
\hline Third & $197.4(25.9)$ & $-4.60(38.6)$ & $-4.07(29.3)$ & -0.015 \\
\hline
\end{tabular}

${ }^{*} P<.05$ (1-tailed); ** $P<.006 ; * * * P<.001$ compared to Placebo. Cohen's d is between Placebo and Alcohol groups. M=mean; $\mathrm{SD}=$ standard deviation.

where the Bonferroni comparisons showed that the first wave yielded higher voltage than the second $(P<.012)$. No effects were observed between the first and the third response or between the last two $\left(P_{S}>.56\right)$ (fig. 2B). An ANOVA of the P2 peak latency, also obtained main effects (F2,58 $=14.8$, $\left.P<.0001, \eta^{2}=0.338\right)$. Bonferroni comparisons showed that the first response was slower than the second $(P<.0001)$ and the third $(P<.0001)$, however no difference was found between the last two responses $(P>.98)$ (fig. 2C). Figure 3 shows the percentage of reduction in the $\mathrm{P} 2$ parameters of the second and third waves when the first wave is $100 \%$. Note an important reduction of $10-20 \%$ of the waves in the three parameters under drug-free baseline conditions due to short-term adaptation. The main reductions occurred in the amplitude and the rate of rise of the second wave. Slightly smaller effects were observed in the third waves and the peak latency.

The possibility that the rate of rise in the EPs correlated with its amplitude and peak latency was tested by separate regressions for each of the two parameters on rise rate. Fig. 4 illustrates these relationships. A faster rise rate was associated with higher P2 wave amplitude for the first $(\mathrm{F} 1,28=$ 115.7, $P<.0001$; Slope $\mathrm{B}=7.93 ; \mathrm{SE}=.74)$, second $(\mathrm{F} 1,28=183.6, P<.0001$; Slope $\mathrm{B}=7.11 ; \mathrm{SE}=$ $.53)$ and the third $(\mathrm{F} 1,28=75.0, P<.0001$; Slope B $=6.27 ; \mathrm{SE}=.72$ ) responses. No significant results were observed for peak latency and rise rate within any wave position $(P S>.61)$.

\section{TREATMENT EFFECTS}

Blood Alcohol Concentration (BAC). The BACs of all participants were measured before and after alcohol or placebo drinks were consumed. The placebo group had zero BAC measures during the test. In the alcohol group, measurements started at 20 minutes after the drinking session began with a mean peak BAC of $55 \mathrm{mg} / 100 \mathrm{ml}$ and then at about 60 minutes with an averaged rising BAC of $80 \mathrm{mg} / 100 \mathrm{ml}$. The subsequent BAC measures showed the mean peak BAC of $86 \mathrm{mg} / 100 \mathrm{ml}$ (SD 

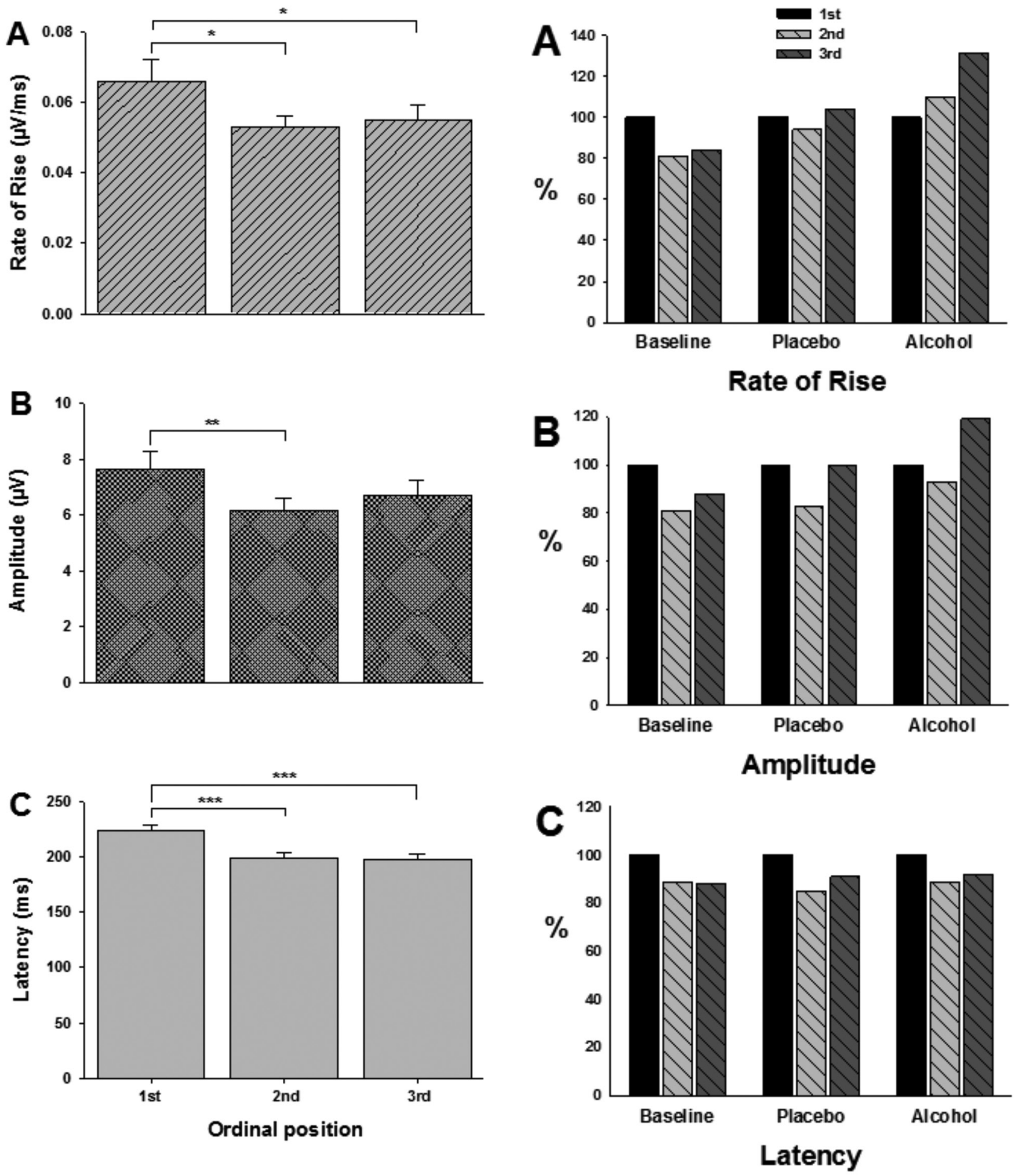

Figure 2 - P2 parameters according to the ordinal position of the stimuli under drug-free conditions. A. P2 rise rate was swifter in the first than in the second or third stimuli. B. The P2 amplitude was higher for the first than for the second stimuli. C. P2 peak latency was slower in the first than in the second or third stimuli. Vertical bars show standard errors of the mean. $* P<.02 ; * * P<.004 ; * * * P<.0001$.

Figure 3 - Percentage of change of the P2 rate of rise (A), amplitude (B) and peak latency (C) according to the order of presentation $\left(1^{\text {st }}, 2^{\text {nd }}\right.$ and $\left.3^{\text {rd }}\right)$ of the $\mathrm{P} 2$ waves on the train. The measures of the first waves were normalized as $100 \%$ in all cases. Baseline is the pre-drug condition and Placebo and Alcohol are the groups. 


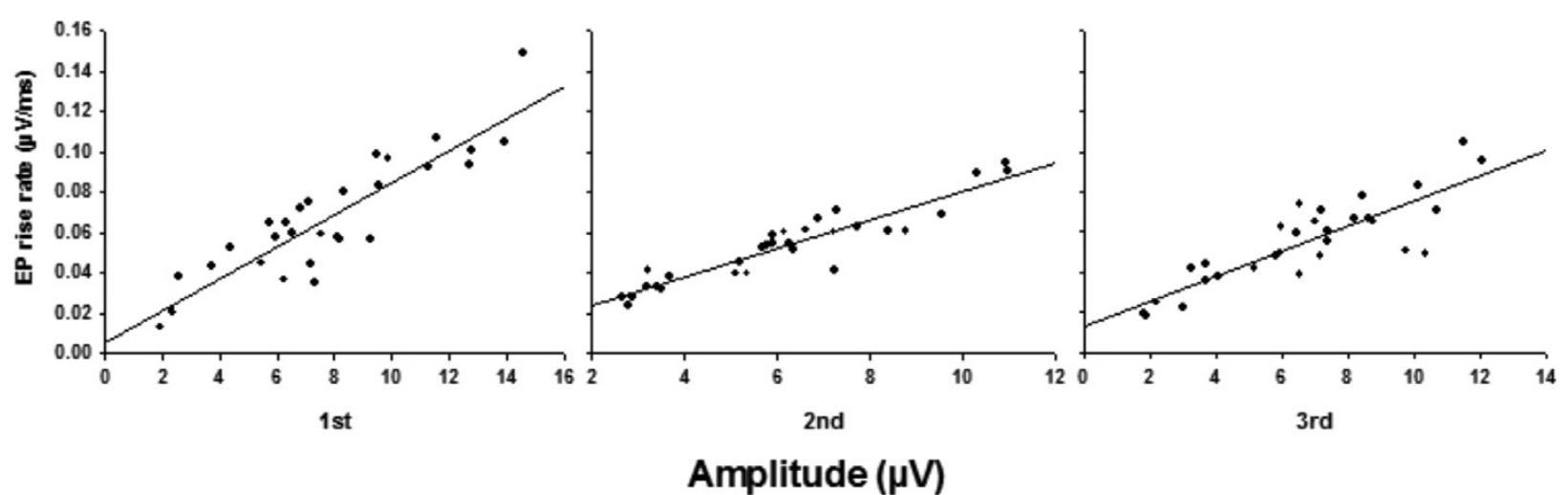

Figure 4 - Scatter plots of data from tests with the first, second and third stimuli show the positive relation between P2 rise rate and amplitude under drug-free condition. The solid lines indicate the least squares regression lines (see details in the text).

= 14) was attained at 72 minutes and then began to decline. The beverage rating scale completed by all participants showed that no one who received a placebo rated the beverage as containing no alcohol. These results indicate that the placebo appeared to be credible. The mean rating of the drink in the placebo group was equivalent to $2.1(S D=2.3)$ bottles of $5 \%$ beer. The experimental group had a mean rating of $6.8(S D=2.3)$.

Alcohol effects. Changes in the averaged 3-position EPs showed differences between alcohol and placebo groups. Table I presents the drug-free baseline measures and alcohol and placebo group mean $(S D)$ change scores for each dependent variable. The Cohen's $d$ shows the size of the effect in the sample. Alcohol was expected to decrease the rate of rise of the EPs. This slowing effect would be indicated by a large negative change score in figure 5A $(P<.00051$-tailed, Cohen's $d=1.43)$. Table I shows that the group means differ in the predicted direction. A planned comparison of the change in P2 rate of rise by the groups is significant for the first, $t(28)=3.01, P<.0001,1$-tailed; second $t(28)=3.59, P<.0001,1$-tailed; and the third $t(28)=1.77, P<.043,1$-tailed, responses. The amplitude of the P2 was also affected by alcohol when compared to that of the placebo. The negative change in the amplitude of the alcohol group in figure $5 \mathrm{~B}$, indicates it became significantly lower than the placebo group $(P<.001,1$-tailed, Cohen's $d=1.28$ ). A planned comparison of the change in $\mathrm{P} 2$ amplitude by the groups is significant for the first, $t(28)=3.19, P<.0015,1$-tailed; and the second, $t(28)=2.97, P<.003,1$-tailed; but not the third, $t(28)=1.60, P>.122$, waves. The change in peak latency in the alcohol group was not significantly different from that of the placebo group $(P>.66$, Cohen's $d<-0.16$ ) or in any ordinal position ( $P S>$ .31). The alcohol effects on the adaptation process are shown in Fig 3. The placebo group showed similar reductions to those obtained in the baseline test, mainly for the latency and amplitude of the second wave, with almost no effects to the rise rate parameter. On the other hand, the alcohol group presented smaller reductions for the amplitude (fig. 3B) and for the peak latency (fig. 3C) of the second wave and values above $100 \%$ for the amplitude of the third wave (fig. 3B) and the rise rate (fig. 3A) of the second and third waves.

In summary, the results showed that a moderate dose of alcohol slowed the rate of rise and reduced the amplitude of the P2 component of the evoked potentials on a train of auditory stimuli. Alcohol affected the $\mathrm{P} 2$ parameters acting against habituation mechanisms. Drug-free baseline measures indicated that the first wave rises faster but reaches the peak later at the expense of bigger amplitude compared with the second and the third waves. 

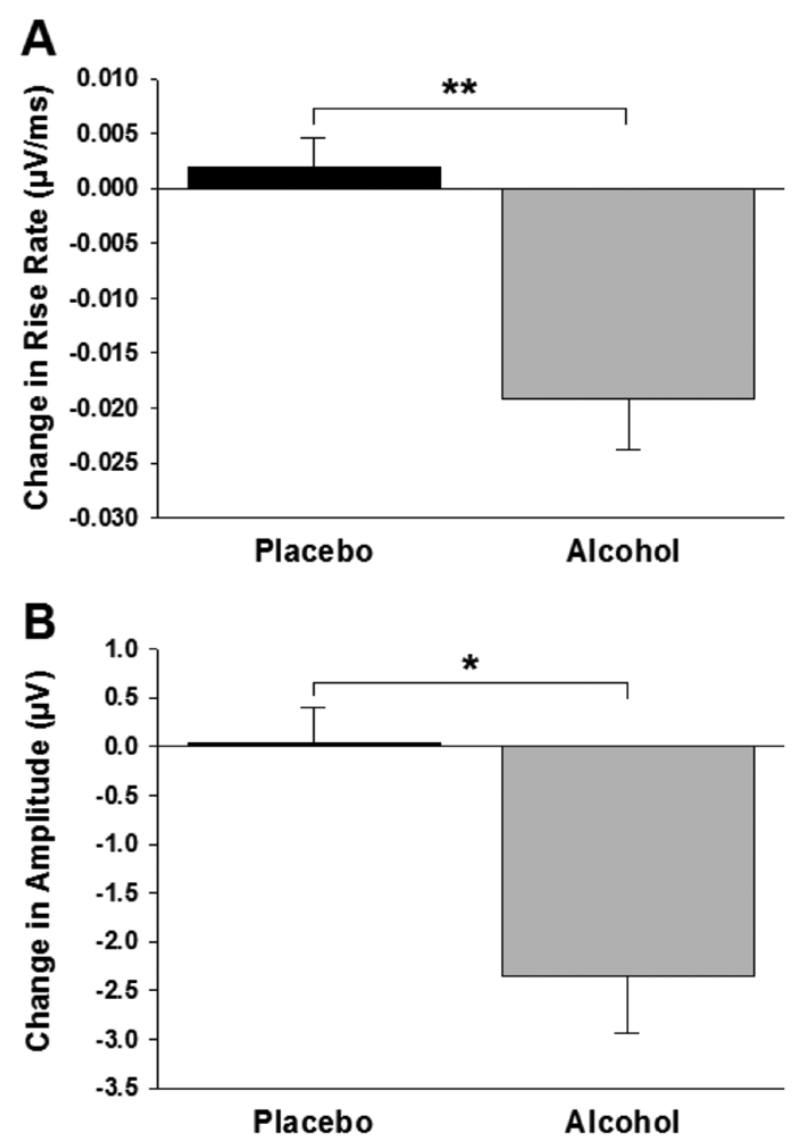

Figure 5 - Mean change in the P2 rise rate and amplitude in alcohol and placebo groups. Zero represents the drug-free baseline level of performance. A negative change indicates a slower rate of rise (A) and lower amplitude (B) in the P2 waves. These changes are only evident in the alcohol group. Vertical bars show standard errors of the mean. ${ }^{*} P<.001$, 1-tailed; $* * P<.0005,1$-tailed.

\section{DISCUSSION}

This experiment is the first to test alcohol effects on the complete set of parameters (peak latency, amplitude and rise rate) of the first, second and third EPs on a train of auditory stimuli. This enabled the study of the dynamics of these parameters in the short-term adaptation process and their sensitivity to alcohol. The results showed that a moderate dose of alcohol impaired the P2 rise rate and amplitude but not the peak latency, when compared to placebo. The drug also tends to reduce the habituation process increasing the rate of rise and the amplitude parameters. The rate of rise parameter proved to be more sensitive to alcohol but more resistant to habituation.

The reduction in the P2 amplitude observed in this work is in agreement to Teo and Ferguson (1986), Rohrbaugh et al. (1987), Oscar-Berman (1987), Jääskeläinen et al. (1996), Porjesz and Begleiter (1996), Noldy (1998), Bartholow et al. (2003a) and Martin and Garfield (2006). Although the alcohol-related increment in the peak latency of many brain potentials is a common finding (Teo and Ferguson 1986, Jääskeläinen et al. 1998, Bartholow et al. 2003b, Marinkovic et al. 2004), it is not uncommon that the latency is found unchanged or reduced (Gross et al. 1966, Slawecki et al. 2000, Martin and Garfield 2006). This discrepancy is probably due, at least in part, to the complexity of the task involved (Bartholow et al. 2003b). Because the late latency brain potentials are index of cognitive processing operations (Bartholow et al. 2003a) and involve higher order neuronal networks of the frontal cortex and auditory regions of the hippocampus (Hillyard et al. 1973, Hillyard and Picton 1979, Woldorff and Hillyard 1991, Johnson and Yonovitz 2007), the observed reductions in the amplitude and rate of rise parameters in this study indicate that alcohol tends to decrease the level of alertness and attentiveness and then, the efficiency to interpret and process sensory-relevant information, impairing the working function memory (Bartholow et al. 2003a, b).

The alcohol-related decrease in the $\mathrm{P} 2$ rate of rise was also similar to that in the OSP observed in a previous work (Hernández and Vogel-Sprott 2010a). The amplitude was also reduced in the two waves but only in the P2 was significance attained. On the other hand, the alcohol effects on the peak latency were different because this measure was increased in the OSP with no effect on the P2. Then, the rate of rise was the only parameter modified in the same fashion by alcohol in both, P2 and OSP. This is probably because they could share the same 
intrinsic mechanisms; nevertheless, the observed differences in the other parameters suggest that the two waves are generated by different neuronal populations. These results support the idea that the rate of rise parameter is able to provide some new information which cannot always be obtained by the more common amplitude or latency measures. Figure 6 helps to understand this statement. It shows that any two waves can have the same rise rate but differ in amplitude and peak latency (fig. $6 \mathrm{~A})$; or change in their rise rate and peak latency but keep the same amplitude (fig. 6B); or even change their rate of rise and amplitude keeping the same latency (fig. 6C). Of course, the two waves could differ in all three measures (fig. 6D). It is interesting that the faster rate of rise of the first P2 was not accompanied by a shorter latency in drug-free conditions. Instead, this potential showed higher peak latencies than the second and third to the expense of higher amplitudes (as in the fig. 6D; see also fig. 2B and 2C). If only the increments in latency and amplitude were obtained, ignoring the rate of rise of the curves, it would be impossible to differentiate between the waves shown in Figure $6 \mathrm{~A}$ and that shown in the Figure 6D. Therefore, the recordings of the rate of rise permit a better understanding of the dynamics of these potentials.

Under drug-free baseline conditions, the second P2 waves were lower than the first, due to habituation, which is common in late evoked potentials (Prosser et al. 1981, Polich et al. 1988, Johnson and Yonovits 2007). A new outcome obtained in this paper is that the rate of rise also showed significant reductions in the second response. The same pattern was observed for the peak latency, although this parameter has been reported to be more stable (Prosser et al. 1981). The normal reductions observed in baseline were maintained in the placebo group, but not in the alcohol group. The subjects that received alcohol showed lesser reductions in the peak latency and no reduction but facilitation in the amplitude and rate

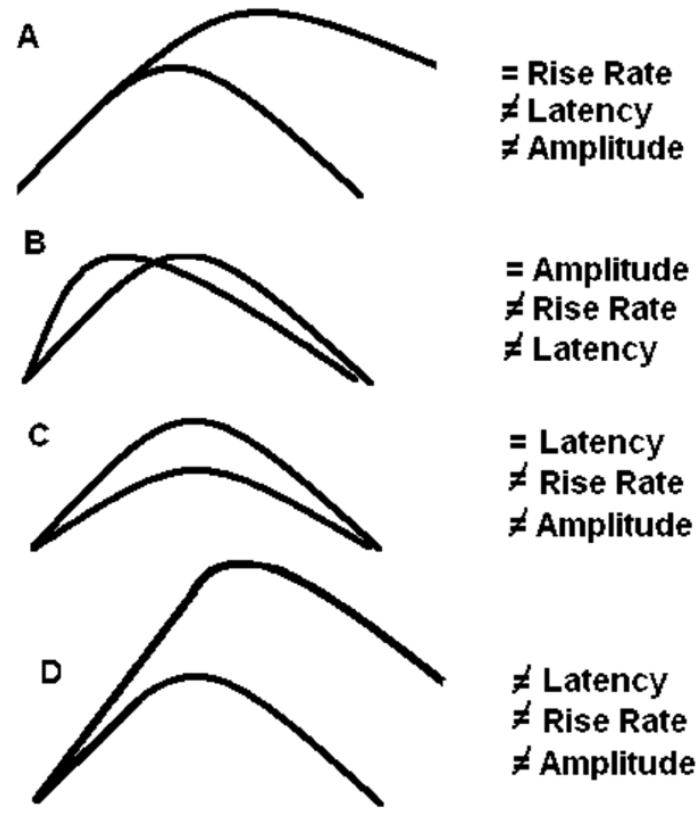

Figure 6 - Drawings of pairs of waves showing similarities $(=)$ and differences $(\neq)$ with respect to their parameter relationships. The waves can be equal in their rate of rise $(\mathbf{A})$, their amplitude $(\mathbf{B})$, or their latency $(\mathbf{C})$ but are different in the other measures. The two waves can also be different in all their parameters (D).

of rise parameters. These results suggest that while some cortical responses become smaller and slower after moderate drinking of alcohol, some neural processes related to short-term adaptation are affected in the opposite direction. The rate of rise was more resistant to habituation than latency and amplitude. The alcohol effects against habituation resemble the response inhibition model proposed by Vogel-Sprott (1992) and Vogel-Sprott et al. (2001). This model states that alcohol impairs a form of response inhibition, such that when certain stimuli or events prompt people to inhibit a given response or behavior, the alcohol consumption is able to impair that inhibition mechanism (e.g. a teenager wants to drive the car but his dad denies permission, but under the influence of alcohol, the teenager ignores his dad's order and takes the car). In this case, the normal inhibition of P2 parameters due to habituation is "disinhibited" by 
alcohol consumption. Further experiments will be necessary to corroborate the role of alcohol on the habituation mechanisms.

This is important because the habituation of auditory evoked potentials is essential for understanding the process of attention, not only within the auditory neural networks but also in the audiological clinical practice (Johnson and Yonovitz 2007).

The P2 parameters did not differ between groups in the drug-free baseline measures as expected because they arrived in the laboratory in the same condition and received the same instructions. The new evidence suggesting that acute alcohol dosing affects P2 parameters for auditory stimuli, directs future research questions specifically with regard to the issue of the reproducibility of the effect with other sensory processes. It is also important to note that there are many constraints in this research: the use of only one scalp site for all the recordings is a great limitation of the study. We used the electrode placement at $\mathrm{Cz}$ with reference and ground electrodes on the ears because it is the best arrangement for OSP recordings (Bullock et al. 1994) and it is also the main scalp site where late latency auditory potentials have been obtained (Picton and Hillyard 1974, Picton et al. 1974). Then, more research about dynamic changes of the brain waves at different electrode placements on the scalp will be necessary. The findings are based on male social-drinking university students, and additional research is needed to determine whether similar results would be obtained with older men and women, heavier drinkers, or those with family histories of alcoholism. The range of BACs that generate these effects on measures of EPs components, and how these results might differ when BACs are rising or declining, are other important topics for future research.

In summary, this study showed that an acute dose of moderate alcohol is able to affect some parameters of the P2 waves and their short-term adaptation process, occurring at the beginning of a train of auditory stimuli. The rate of rise was slowed and the amplitude was reduced in the alcohol group compared to placebo, while the peak latency was not affected. The P2 rate of rise parameter proved to be more sensitive to alcohol than the amplitude and peak latency. This was similar to the OSP rise rate, suggesting common neural mechanisms of generation. The rate of rise was also the most resistant parameter to habituation process. Alcohol seems to act against habituation, which is in agreement to the response inhibition model. These results are a new finding that raise many interesting questions about the factors and processes that might account for these effects which are relevant in neuropsychological applications, cognitive research and clinical applications like neurological diagnosis.

\section{ACKNOWLEDGMENTS}

The advice and contribution of Dr. Muriel VogelSprott, Professor of Psychology, Department of Psychology, University of Waterloo, Waterloo, Ontario, is gratefully acknowledged. She participated heavily in the initial stage of this study and passed away on September 27, 2009.

\section{RESUMO}

Esta é a segunda parte de uma pesquisa que teve como objetivo estudar os efeitos do álcool sobre os processos eletrofisiológicos em estudantes voluntários. A primeira parte mostrou que o álcool diminuiu o "Omitted Stimulus Potential" (OSP). Este trabalho estudou os efeitos do etanol sobre os parâmetros (ou seja, taxa de crescimento, amplitude e latência de pico) do componente P2 dos potenciais evocados (EPS) gerados por trens de estímulos auditivos. A hipótese aqui levantada é que, se ondas P2 e OSP compartilham alguns processos neurais comuns, então o álcool também deve afetar estes parâmetros específicos. Uma dose de $0,8 \mathrm{~g} / \mathrm{kg}$ de álcool ou de um placebo $(0 \mathrm{~g} / \mathrm{kg})$ foi administrada a dois grupos de 15 jovens que foram testados antes, e novamente 
após o tratamento. A mudança de pré-/pós-tratamento em cada uma das medições foi utilizada para avaliar os efeitos do tratamento. Os resultados mostraram que, em comparação com o placebo, o álcool reduziu a taxa de crescimento de $\mathrm{P} 2$ e reduziu sua amplitude, sem efeitos sobre o pico de latência. A taxa de crescimento é mais sensível ao álcool, porém mais resistente ao processo de adaptação. O álcool se assemelha ao modelo de inibição da resposta que atua contra a adaptação. A taxa de crescimento da P2 e as ondas OSP são afetadas pelo álcool de um modo semelhante, sugerindo mecanismos neurais semelhantes.

Palavras-chave: álcool, auditivo, potenciais evocados, parâmetros.

\section{REFERENCES}

Bartholow BD, Pearson M, Gratton G and FABiani M. 2003b. Effects of alcohol on person perception: A social cognitive neuroscience approach. J Pers Soc Psychol 85: 627-638.

Bartholow BD, Pearson M, Sher KJ, Wieman LC, FABIANI M AND GRATTON G. 2003a. Effects of alcohol consumption and alcohol susceptibility on cognition: A psychophysiological examination. Biol Psychol 64: 167-190.

Bullock TH, Karamürsel S, ACHIMOWICZ JZ, McClune MC AND BAŞAR-EROGLU C. 1994. Dynamic properties of human visual evoked and omitted stimulus potentials. Electroencephalogr Clin Neurophysiol 91: 42-53.

DONCHIN E AND ISREAL JB. 1980. Event-related potentials and psychological theory. In: KORNHUBER HH AND DEECKE L (Eds), Motivation, motor and sensory processes in the brain: Electrical potentials, behavior and clinical use, New York: Elsevier, New York, USA, p. 697-715.

EAsdon C, Izenberg A, ARMilio ML, Yu H AND Alain C. 2005. Alcohol consumption impairs stimulus- and errorrelated processing during a Go/No-Go Task. Cognitive Brain Res 25: 873-883.

Fillmore M AND Vogel-SprotT M. 1994. Psychomotor performance under alcohol and under caffeine: expectancy and pharmacological effects. Exp Clin Psychopharm 2: 319-327.

FILLMORE M AND VOGEL-SPROTT M. 1995. Expectancies about alcohol induced motor impairment predict individual differences in responses to alcohol and placebo. J Stud Alcohol 56: 90-98.

FILLMORE MAND VOGEL-SPROTTM. 1997. Resistance to cognitive impairment under alcohol: The role of environmental consequences. Exp Clin Psychopharm 5: 251-255.

Gross MM, Begleiter H, ToBin M AND Kissin B. 1966. Changes in auditory evoked response induced by alcohol. J Nerv Ment Dis 143: 152-156.
HERNÁNDEZ OH AND VOGEL-SPROTT M. 2009. OSP parameters and the cognitive component of reaction time to a missing stimulus: Linking brain and behavior. Brain Cognition 71: 141-146.

HERNÁNDEZ OH AND VogEL-SpRotT M. 2010a. Alcohol slows the brain potential associated with cognitive reaction time to an omitted stimulus. J Stud Alcohol Drugs 71: 268-277.

HERNÁNDEZ OH AND VOGEL-SPROTT M. 2010b. Reaction time and brain waves in omitted stimulus tasks: A multisensory study. J Psychophysiol 24: 1-6.

HernándeZ OH, Vogel-SprotT M, Huchín-RAmirez TC AND AKE-EsTRADA FR. 2006. Acute dose of alcohol affects cognitive components of reaction time to an omitted stimulus: differences among sensory systems. Psychopharmacology 184: 75-81.

HERnÁNDEZ OH, Vogel-SPROTt M AND Ke-AZNAR VI. 2007. Alcohol impairs the cognitive component of reaction time to an omitted stimulus: a replication and extension. J Stud Alcohol Drugs 68: 276-281.

HiLlyard SA, Hink RF, SCHWENT VL AND PICTON TW. 1973. Electrical signs of selective attention in the human brain. Science 182: 177-180.

HILlYARD SA AND PICTON TW. 1979. Event-related brain potentials and selective information processing in man. In: DESMEDT J (Ed), Progress in clinical neurophysiology. Cognitive components in cerebral event-related potentials and selective attention, Deutschland: Basel Karger, p. 1-52.

JÄÄSKELÄINEN IP ET AL. 1998. Effects of naltrexone and ethanol auditory event-related brain potentials. Alcohol 15: 105-111.

JÄÄSKELÄINEN PP, NÄÄTÄNEN R AND SILLANAUKEE P. 1996. Effect of acute ethanol on auditory and visual eventrelated potentials: A review and reinterpretation. Biol Psychiat 40: 284-291.

JOHNSON A AND YONOVITZ A. 2007. Habituation of auditory evoked potentials: The dynamics of waveform morphology. Aust NZ J Audiol 29: 77-88.

Krogh HJ, Khan MA, Fosvig L, Jensen K And Kellerup P. 1978. N1-P2 component of the auditory evoked potential during alcohol intoxication and interaction of pyrithioxine in healthy adults. Electroencephalogr Clin Neurophysiol 44: 1-7.

MARINKOVIC K, HALGREN E AND MALTZMAN I. 2004. Effects of alcohol on verbal processing: An event-related potential study. Alcohol Clin Exp Res 28: 415-423.

MARTIN FH AND GARFIELD J. 2006. Combined effects of alcohol and caffeine on the late components of the event-related potential and on reaction time. Biol Psychol 71: 63-73.

NOLDY N. 1998. Acute and chronic effects of social drinking: event-related potentials and quantified EEG. In: SNEL J AND LORIST M (Eds), Nicotine, caffeine, and social drinking: Behavior and brain function, Amsterdam: Harwood Academic Publishers, Amsterdam, Netherlands, p. 289-299.

OSCAR-BERMAN M. 1987. Alcohol-related ERP changes in cognition. Alcohol 4: 289-292. 
PICTON TW AND HILlYARD SA. 1974. Human auditory evoked potentials: II: Effects of attention. Electroencephalogr Clin Neurophysiol 36: 191-199.

Picton TW, Hillyard SA, Krausz HI and Galambos R. 1974. Human auditory evoked potentials: I. Evaluation of components. Electroencephalogr Clin Neurophysiol 36: 179-190.

Polich J, Aung M AND DALESSIO DJ. 1988. Long latency auditory evoked potentials: Intensity, inter-stimulus interval, and habituation. Pavlovian J Biol Sci 23: 35-40.

PORJESZ B AND BEGLEITER H. 1996. Effects of alcohol on electrophysiological activity of the brain. In: BEGLEITER H AND BENJAMIN K (Eds), Alcohol and alcoholism: The pharmacology of alcohol and alcohol dependence, New York: Oxford University Press, New York, p. 207-247.

PRITCHARD WS. 1981. Psychophysiology of P300. Psychol Bull 89: 506-540.

Prosser S, Arslan E And Michelini S. 1981. Habituation and rate effect in the auditory cortical potentials evoked by trains of stimuli. Arch Oto-Rhino-Laryn 233: 179-187.

RohrbaUGH JW, StAPLETON JM, PARASURAMAN R, ZUBOVIC EA, Frowein HW, VArner JL, Adinoff B, LANE EA, ECKARDT MJ AND LINNOILA M. 1987. Dose-related effects of ethanol on visual sustained attention and event-related potentials. Alcohol 4: 293-300.

RUGG MD AND COLES MGH. 1995. Electrophysiology of mind: Event-related brain potentials and cognition. New York: Oxford University Press, 220 p.
SlaweCKI CJ, SOMES C AND EHLERS CL. 2000. Effects of prolonged ethanol exposure on neurophysiological measures during an associative learning paradigm. Drug Alcohol Depen 58: 125-132.

SOMmer W, LeUthold H AND HeRmanutz M. 1993. Covert effects of alcohol revealed by event-related potentials. Percept Psychophys 54: 127-135.

SutTon S, Braren M AND ZuBIN J. 1965. Evoked-potential correlates of stimulus uncertainty. Science 150: 1187-1188.

SUTTON S, TUETING P, ZUBIN J AND JOHN ER. 1967. Information delivery and the sensory evoked potential. Science 155 : 1436-1439.

TEORKCANDFERGUSONDA. 1986. The acute effects of ethanol on auditory event-related potentials. Psychopharmacology 90: 179-184.

VogEL-SprotT M. 1992. Alcohol Tolerance and Social Drinking: Learning the Consequences. New York: Guilford Press, $221 \mathrm{p}$.

Vogel-Sprott M, EAsdon C, Fillmore M, Finn P And JUSTUS A. 2001. Alcohol and behavioral control: Cognitive and neural mechanisms. Alcohol Clin Exp Res 25: 117-121.

WOLDORFF MG AND HILLYARD SA. 1991. Modulation of early auditory processing during selective listening to rapidly presented tones. Electroencephalogr Clin Neurophysiol 79: 170-191.

WOLPAW JR AND PENRY JK. 1978. Effects of ethanol, caffeine and placebo on the auditory evoked response. Electroencephalogr Clin Neurophysiol 44: 568-574. 